
Transfusion Medicine
and Hemotherapy
Clinical Information - Klinische Information

Transfus Med Hemother 2008;35:42-49

DOI: $10.1159 / 000111480$
Received: October 26, 2007

Accepted: November 13, 2007

Published online: December 3, 2007

\title{
Influenza Virus
}

\author{
Arbeitskreis Blut, Untergruppe «Bewertung Blutassoziierter Krankheitserreger»
}

\section{Current Knowledge about the Pathogen}

\subsection{Characteristics of Influenza Viruses}

Influenza viruses are members of the family Orthomyxoviridae. This family represents enveloped viruses the genome of which consists of segmented negative-sense single-strand RNA segments. There are four genera of this family: types A, $\mathrm{B}, \mathrm{C}$ and Thogotovirus, of which, however, only genera A and $\mathrm{B}$ are clinically relevant for humans. The eight genome segments of influenza A and B viruses are loosely encapsidated by the nucleoprotein. The polymerase complexes consisting of the three polymerase proteins PB1, PB2, and PA are located at the ends of the nucleocapsids. These helical capsids are encircled by the M1 matrix protein and by a host-derived lipid bilayer envelope in which the virus surface glycoproteins haemagglutinin (HA) and neuraminidase (NA) as well as the M2 matrix protein are embedded [1]. The HA is synthesized as precursor protein and cleaved by cellular serine proteases into the functional proteins HA1 and HA2. The amino acid sequence at the cleavage site determines HA processing by cellular proteases and thus, also the organ tropism. Mutations at the cleavage site of avian influenza viruses may lead to an insertion of alkaline amino acids. Ubiquitous proteases such as furin can cleave such a mutated HA and, as a consequence, permit systemic spreading of the virus. This mechanism changes a lowly pathogenic into a highly pathogenic avian influenza virus and has been associated so far only with subtype $\mathrm{H} 5$ and $\mathrm{H} 7$ viruses.

Influenza virus as an enveloped virus is relatively vulnerable to damaging environmental impacts. Depending on environmental conditions (e.g. humidity and temperature), however, it can survive up to several hours and in water at low temperatures (e.g. $<20{ }^{\circ} \mathrm{C}$ ) also considerably longer (up to several months). Influenza viruses are sensitive to lipid solvents and detergents. They are also vulnerable to heat and a low $\mathrm{pH}$, depending on the virus type. Influenza A viruses with uncleaved
HA are obviously more stable (loss of infectivity at $\mathrm{pH}<4.5$ ) than viruses with cleaved HA (loss of infectivity at $\mathrm{pH}<5$ ) [2].

The most outstanding characteristic of influenza viruses is their rapid evolution which leads to its great variability. This is the case especially with influenza A viruses. According to the antigenic properties of their envelope proteins, influenza A viruses are subdivided into a number of subtypes. 16 different HA and 9 different NA subtypes have been identified so far. The nomenclature system follows the pattern $\mathrm{H}(\mathrm{x}) \mathrm{N}(\mathrm{y})$ including the host of origin, geographical location, strain number, and year of isolation $[1,3]$. Influenza $B$ viruses are not further divided into subtypes. The accumulation of point mutations leads to a step-by-step modification of the virus proteins (above all in the two surface antigens HA and NA). This mechanism is described as 'antigen drift' and is also typical of influenza B viruses. The variability of the type B viruses, however, is also characterised by other mechanisms such as insertion and deletion, as the influenza $B$ lines show which have been co-circulating and stable for more than 20 years $[4,5]$. The process of 'antigen shift' (re-assortment) is defined as the exchange of whole genome segments, above all HA genes, which might result in influenza viruses which have a selective advantage compared with their parent viruses. A prerequisite for this re-assortment is simultaneous infection of a cell by two different influenza A viruses. This will result in a variety of different hybrid viruses with different characteristics which they have received from the parent viruses via the individual genome segments. An example is the occurrence of the influenza A/H2N2 subtype in 1957 which superseded the influenza A/H1N1 virus which was dominant until then [6, 7].

Special attention was drawn to the public by the deaths caused in humans by the highly pathogenic avian influenza A/H5N1 subtype. These cases have shown that an entirely new influenza A virus can cause deadly infections in humans. Since the first outbreaks of H5N1-related avian influenza in poultry in South-East Asia in 2003, human H5N1 transmissions with

\begin{tabular}{ll}
\hline KARGER & @ 2008 S. Karger GmbH, Freiburg \\
Fax +49 7614520714 & Accessible online at: \\
$\begin{array}{l}\text { E-mail Information@Karger.de } \\
\text { www.karger.com }\end{array}$ & www.karger.com/tmh
\end{tabular}

Prof. Dr. med. Rainer Seitz

Paul-Ehrlich-Institut

Paul-Ehrlich-Straße 51-59, 63225 Langen (Germany)

Tel. +49 6103 77-26 01, Fax -1250

E-mail seira@pei.de 
high mortality have occurred in 10 countries. [8]. It is possible that this virus will adapt better to humans and will then be able to spread among the human population.

\subsection{Infection and Infectious Disease}

Influenza viruses are assumed to be transmitted predominantly by aerosol infection, i.e. relatively large droplets $(>5 \mu \mathrm{m})$ created particularly while talking, coughing, or sneezing, thus entering the mucosae through contact at small distances. Individual publications, however, have also suggested that transmission might occur by so-called droplet cores which are smaller $(<5 \mu \mathrm{m})$ and able to remain in the air for longer periods (aerogenic transmission). In addition, transmission can occur by direct contact with virus-contaminated surfaces (e.g. shaking hands) and subsequent mouth-nose contact. After infection the viruses replicate in the nasal and laryngeal mucosae. This replication also affects the lower airways as the infection progresses.

A clinical characteristic of human influenza is a sudden rise in body temperature to $>38.5{ }^{\circ} \mathrm{C} 1-3$ days following infection. Other symptoms include headache, limb ache, tiredness, general faintness and dry cough. Infectivity can start already shortly $(<24 \mathrm{~h})$ before the onset of the clinical symptoms and usually persists 3-5 days. Small children can excrete the viruses earlier and over a longer period of time than adults. The most serious outcomes are peracute death within only few hours and primary influenza pneumonia. Encephalitis or myocarditis can also occur. Serious and fatal outcomes with primary viral and viral-bacterial pneumonia are known and have been communicated in single case reports in children and young adults $[9,10]$. Complications occur particularly in older patients with primary disease (chronic heart or lung disease, metabolic disorders such as diabetes, immune disorders etc.). Such cases, above all, can involve pneumonia by bacterial superinfection (e.g. Streptococcus pneumoniae, Haemophilus influenzae, Staphylococcus aureus) [11,12]. In children, administering salicylates may lead to Reye syndrome. Reye syndrome describes an acute cerebral function disorder. The latter occurs as a result to liver damage, usually in connection with the ingestion of acetylsalicylic acid after febrile virus infections. The situation is different with infections of humans with avian influenza virus of the H5N1 subtype which has been circulating among the wild fowl population in South-East Asia since 2003, but also in the Middle East, in Central Africa and in South and Central Europe since autumn 2005. After a prolonged incubation period of up to 7 days, also here the characteristic initial symptoms were acute rise in body temperature $\left(>38{ }^{\circ} \mathrm{C}\right)$ and influenza-like symptoms, but the respiratory tract was not involved in all patients. Frequently observed symptoms included watery diarrhoea, vomiting and pain in the abdomen and the chest. Also the occurrence of encephalitis was often described. Thus, an infection of tissues outside the respiratory tract occurs so that short-term viraemia has to be assumed (cf. 4.1). This could be confirmed by laboratory diagnosis in the case of the fatal outcome of an H5N1 infection in a boy in Thailand [13]. Taken together, the course of the disease is extremely aggressive, resulting in rapid worsening of the patient's condition and a high mortality rate $[14,15]$.

\subsection{Epidemiology}

While influenza B infections occur only in humans, influenza A viruses can also infect pigs and horses. Wild birds, above all water fowl, in which all HA and NA types occur are considered as a reservoir for influenza A viruses [16,17]. Infections with the so-called highly pathogenic subtypes $\mathrm{H} 5$ and $\mathrm{H} 7$ can occur in chickens but also other types of birds and cause the clinical picture of classical avian plague (highly pathogenic avian influenza; HPAI), often also called bird flu. The cause for this is that the virus can replicate throughout the bird's body, resulting in disease with a high mortality rate.

Since 1977, a co-circulation of the subtypes influenza A/H3N2 and A/H1N1 as well as influenza B can be observed in humans. Human viruses of the subtype H1N2 were first observed sporadically in 1977, but not in the following years until the season of 2001/2002, when they caused local outbreaks in some countries. These viruses, however, did not become epidemiologically significant and have not been identified since 2005 [18].

Human influenza virus infections have a world-wide distribution. Seasonal influenza epidemics occur regularly both in the Northern and the Southern hemispheres each winter. Due to the seasonal shift, the winter influenza outbreak of the Southern hemisphere occurs during the summer of the Northern hemisphere. These influenza epidemics are estimated to cause approximately 500,000 deaths per year world-wide [19]. Little is known about the epidemiology of influenza in tropical countries, but it is assumed that influenza can occur throughout the year there.

Despite the pronounced seasonal dependency, influenza infections in the respective countries can also occur outside the normal influenza epidemics and can even lead to locally and temporally limited outbreaks. During the annual influenza epidemics, an estimated rate of $10-15 \%$ of the population is affected. The influenza epidemics can also be clearly distinguished from each other by the degree of severity. National influenza surveillance in Germany rests on three pillars: identification and characterization of circulating viruses by the Nationales Referenzzentrum für Influenza (National Reference Centre for Influenza) at the Robert Koch-Institut, the sentinel system of the Arbeitsgemeinschaft Influenza (AGI; Influenza Working Party) and the obligation to report the identification of virus by diagnostics in the laboratory. In the past few years, the seasons of 2002/2003 and 2004/2005 were characterised by extraordinarily high influenza virus activity. During the period 
of $2000 / 2001$ to $2004 / 2005$, the annual influenza outbreaks caused approximately 2,900,000 excess consultations, 900,000 sick notes among the working population (estimated for the age groups 16-60 years), 14,000 additional hospitalisations, and approximately 10,000 deaths compared with the periods without influenza virus circulation [20,21]. The majority of influenza-associated deaths concerns the age group of the over 60 -year-olds, not only in Germany but also in other countries [20, 22].

Influenza pandemics are characterised by the occurrence (recurrence) of influenza A subtype against which the majority of the human population is not immune, thus causing a worldwide epidemic. The past century was characterised by three major pandemics: The Spanish Flu of 1918 (H1N1) caused about 40 million deaths, while the death rates of Asian influenza of 1957 (H2N2) and Hong Kong Flu of 1968 (H2N3) were estimated at 1-2 million and 0.75-1 million deaths, respectively [19].

Special public attention was paid to the outbreak of classical avian influenza in the Netherlands and Belgium in spring 2003 by influenza A H7N7, and the influenza A H5N1 epidemic which started in South-East Asia in 1998, because they also affected humans. It is suspected that the next pandemic could also be caused by the highly pathogenic influenza virus of the H5N1 subtype. Up to now, the virus has circulated exclusively in (wild) birds. Humans have been infected only in isolated cases. Since the first human H5N1 outbreaks in 2003, 331 cases of infection and 202 deaths due to H5N1 have been officially confirmed by the WHO (data as of October 12, 2007). It is the age group of the patients that strikes us here, since mainly adolescents and young adults were affected. At present, two endemic areas with recurrent human infections and deaths have formed: Indonesia and Egypt. A genetic predisposition has been discussed since outbreaks within a family affected mainly consanguineous relatives.

\subsection{Detection Methods and Their Significance}

A number of methods are available for the direct detection of an influenza virus infection. As a rule, these methods use clinical materials of the upper respiratory tract (nose, pharynx), and, if indicated, e.g. in case of $\mathrm{H} 5 \mathrm{~N} 1$, also the lower respiratory tract. Serological methods now play a subordinate role in diagnosing acute infection.

\subsubsection{Serology}

Influenza virus-specific antibodies in the serum can be determined as total antibody levels or differentiated as single antibody sub-classes (IgA, IgM, IgG). Methods traditionally used include complement-binding reaction (CBR) and the methods preferably used today such as enzyme immunoassay (EIA) and immunofluorescence test (IFT). More sophisticated methods such as the haemagglutination inhibition test (HIT) and the neutralisation test require specialised reagents and are performed by only few laboratories in Germany. These tests can also provide information about the variant of the virus that caused the infection. An influenza virus infection will result in an IgG titre which persists for decades, but also a CBR titre can be increased during a longer period of time. Therefore, paired serum samples (at the onset of the disease and 10-14 days after the onset of the disease) should be examined for verification of an acute infection. A four-fold increase in the titre is rated as positive verification of the disease. Isolated IgA or IgG detections, however, are only of limited informational value. For both any decisions on treatment and patient management, the results of the antibody determinations would be available too late. Hence, serological methods used to identify an infection are of significance above all for epidemiological studies, for examining the effectiveness of the vaccination or for clarifying outbreaks of the infection. As far as avian influenza is concerned, however, serology is of greater significance. A reliable detection of avian influenza virus such as $\mathrm{A} / \mathrm{H} 5 \mathrm{~N} 1$ is not always possible by means of PCR or virus culture, since it depends above all on the time when the sample is taken and the degree of severity of the disease (www.who.int/csr/don/2006_09_14/en/index.html). The HIT which is very well suited for human influenza detection is not sensitive enough to detect avian influenza viruses. The gold standard here is the virus neutralisation test.

\subsubsection{Virus Culture}

Because of the technical requirements, isolation of influenza virus is carried out in specialised laboratories only under biosafety level 2 conditions. Virus culture is very time-consuming and requires the presence of replication-competent virus particles in the patient sample. Embryonated hen eggs have been used for culturing for decades. This method is still absolutely necessary for culturing reference strains even though cell cultures have been used for primary culturing in the past few years. Madin-Darby canine kidney (MDCK) cells have proven to be particularly suitable. The appearance of a cytopathic effect can require from several days up to 2 weeks. Following this, the culture must be verified by a specific test (ELISA or IFT). To speed up the process, i.e. before the appearance of a cytopathic effect, virus-specific antigen can be detected using IFT (shell vial technique). These rapid culturing methods can produce results after 1-2 days, but are less sensitive. Virus culturing therefore plays a role neither in an out-patient nor in a hospital setting for the reasons mentioned above.

As far as national and world-wide influenza virus monitoring is concerned, however, virus culturing is of basic significance. The German National Reference Centre for Influenza is the competent authority for a comprehensive characterisation of influenza viruses circulating in Germany. The isolated viruses are examined using a panel of specific immunosera in order to determine their similarity with vaccine strains and influenza 
viruses circulating during the past season. In addition, molecular and phylogenetic analyses are performed in order to obtain detailed insights into the evolution of the influenza viruses and ongoing drift events [23, 24]. There is a close collaboration, both at a European level and with WHO institutions, in order to be able to make optimal recommendations on the vaccine compositions for the forthcoming season on the basis of these joint monitoring and analysis data [25].

\subsubsection{Antigen Detection}

Compared with virus culturing, antigen detection tests can be performed faster in any laboratory. For this purpose, commercial tests are available, e.g. IFT or ELISA. These methods provide relatively good results if there is a sufficient amount of virus antigen available in the patient's sample. The IFT is valid only if suitable sample material is available which has to be evaluated by experienced personnel. Methods such as IFT and ELISA can provide results in only a few hours. Specificity of these tests is usually very good but sensitivity is lower than with methods which either detect the virus itself or the viral genome [26-28].

Antigen tests called 'rapid tests' are available for several years. Rapid tests currently available in Germany are EIAs, which somewhat differ both in their format and in the test method. In general, the results can be obtained in approximately 10-15 min. With the exception of one test, they are all able to distinguish between influenza A and B. They are all characterised by high specificity. Data on sensitivity differ between 60 and $100 \%$ in samples of clinically ill individuals. Virus culturing and/or IFT were predominantly used as reference method. Sensitivity of these rapid tests can be compared to that of IFT and EIA $[29,30]$.

\subsubsection{Genome Detection}

Polymerase chain reaction (PCR) is a very sensitive and specific method. With the aid of specific oligonucleotide primers, the required genome sequences are replicated (amplified) in such a way that they can subsequently be detected using various techniques. Previous assays were limited to the use of primers and the analysis of the PCR product in agarose gel [31, 32]. Higher specificity of PCR, however, can be obtained by using specific probes by means of hybridisation blot [33, 34] or PCR-EIA $[35,36]$. Higher specificity can also be obtained by nested PCR [37].

The use of PCR and the methods following PCR for product analysis in diagnostic laboratories requires simplicity, speed, and reproducibility of the methods. More recent 'real time' methods meet these requirements. With the aid of a fluorescence probe, the specific PCR product is detected already while the PCR is being performed by online measurement so that a subsequent product analysis is no longer required. Specific primer/probe sets allow rapid and sensitive detection of influenza viruses in the patient material. A major advantage of this method is the avoidance of contamination since any han- dling of PCR products becomes unnecessary. Depending on the results to be obtained, primers/probes are used which bind to preserved genome areas, thus permitting the general detection of influenza A and separate detection of influenza B viruses. PCR assays for specific sequence segments are used for differentiation into the various HA and NA subtypes of influenza A viruses [38].

\section{Blood and Plasma Donors}

The peculiarities listed for the pandemic case refer to Step 6 of the definition of a pandemic according to the WHO (table 1), to the extent that blood donor services are affected. It is therefore necessary for blood donor services to receive the current epidemiological ratings. In the case of a pandemic, an appropriate and co-ordinated reaction of the blood donor services to the current epidemic situation must be made possible by integrating all blood donor services into the pandemic plans of the 'Länder' (German federal states) and laying down the flow of information.

\subsection{Prevalence and Incidence in Donor Populations}

Reliable data on the prevalence of influenza virus infections in blood donors are not yet available. However, it can be assumed that the prevalence and incidence of the donor collective is comparable with those of the general population.

\subsection{Definition of Exclusion Criteria}

For influenza virus infections, the general exclusion criteria for febrile infections apply pursuant to the haemotherapy guidelines (Hämotherapie-Richtlinien) [40].

\section{Special Precautions to Be Observed during the Pandemic Period}

A risk/benefit analysis could be considered between a breakdown of blood supply and an emergency relaxation of the following donor selection criteria, in close coordination with the competent authorities:

- reduce haemoglobin requirement of 13.5 to $13 \mathrm{~g} / \mathrm{l}$ for men and from 12.5 to $12 \mathrm{~g} / \mathrm{l}$ for women (subject to individual decision by the physician),

- increase donation frequency for platelet apheresis,

- increase age limit for multiple donors to approximately 70 years (subject to individual decision by the physician),

- acceptance of donors already 1 week after recovery from influenza if subjective physical well-being has been restored (subject to the decision by the physician),

- influenza prophylaxis using medicinal products is not an exclusion criterion, if no clinical symptoms have appeared. 
Table 1. Pandemic phases according to the WHO pandemic preparedness plan [39]

\section{Inter-pandemic period}

Phase 1 No new influenza virus subtypes have been detected in humans. An influenza virus subtype that has caused human infection may be present in animals. If present in animals, the risk of human infection or disease is considered to be low.

Phase 2 No new influenza virus subtypes have been detected in humans. However, a circulating animal influenza virus subtype poses a substantial risk of human disease.

Pandemic alert period

Phase 3 Human infection(s) with a new subtype, but no human-to-human spread, or at most rare instances of spread to a close contact.

Phase 4 Small cluster(s) with limited human-to-human transmission, but spread is highly localised, suggesting that the virus is not well adapted to humans.

Phase 5 Larger cluster(s) but human-to-human spread still localised, suggesting that the virus is becoming increasingly better adapted to humans, but may not yet be fully transmissible (substantial pandemic risk).

Pandemic period

Phase 6 Pandemic: increased and sustained transmission in general population. Decisions to be made in Phase 6 whether a country is not yet affected,

a country is affected or has close trade relations or travel between an affected country, activity has decreased, or

a second pandemic wave has occurred

Post-pandemic phase

Return to inter-pandemic period

\subsection{Donor Testing and Significance}

Donor testing for virus genome of influenza virus is not necessary on the basis of the present data situation.

\section{Special Situation during the Pandemic Period}

Donor screening with nucleic acid amplification techniques for the detection of viraemia cannot be introduced immediately from a technical point of view. No validated test systems are available. Up to now, there is no evidence for influenza transmission by blood products. The risk of an infection by blood products compared with the likelihood of infection through social contacts is therefore in all probability negligible. Considering the collection staff shortages to be expected, the use of the additional workload imposed by rapid tests for antigen detection including advice in the event of a positive outcome is questionable compared with the benefit to be expected.

\subsection{Donor Interviews}

Based on the haemotherapy guidelines (HämotherapieRichtlinien) [40], questions to the donor include information on well-being and fever.

\section{Special Situation during the Pandemic Period}

Potential donors should be asked expressly whether he/she cared for influenza patients within the past 7 days prior to donation or had comparatively close contacts with influenzainfected individuals.
Admission for donation should be based on these potential donors' current state of health and protective measures they have taken.

The question of general contact with influenza-infected individuals is of little use during a pandemic period.

\subsection{Donor Information and Counselling}

There is currently no justification for making recommendations regarding donor testing, advice to donors and look-back procedures. Specific donor information takes place.

\section{Special Situation during the Pandemic Period}

To prevent masses of people from meeting in one site, special appointments should be made for blood collection activities. Donors should receive MNS masks on entering the donation site and should be offered a hand disinfectant with emphasis. All blood donor services should prepare appropriate information material for blood donors and blood collection staff and train their staff beforehand.

\section{Recipients}

\subsection{Prevalence and Incidence of Blood-Associated Infections and Infectious Diseases in Recipient Populations}

No recipient-specific data is available on the prevalence and incidence of influenza virus infections. However, it can be assumed that the prevalence of antibodies against influenza 
viruses in these collectives is equivalent to that of the general population. No information is available on influenza virus infections transmitted by blood or blood products.

\subsection{Immune Status (Resistance, Existing Immunity, Immune Response, Age, Exogenous Factors)}

Due to the high antigenetic variability of influenza viruses, the continuously emerging drift variants can cause annual influenza epidemics. For this reason, influenza vaccines must be adapted to the current drift variants each year and used in vaccinations to provide highest possible protection. The WHO provides recommendations on the antigen composition of the vaccine before each influenza season. In Germany, according to the Ständige Impfkommission (STIKO; German Standing Vaccination Committee), above all individuals with an increased risk of developing a severe influenza infection (persons over 60 years, patients with underlying disease, chronically ill and immunocompromised persons and persons with an increased risk, such as medical staff) should be immunised yearly. People are protected by the vaccine after 2 weeks. The protection rate is about $70-90 \%$ if the vaccine strains coincide well with the circulating strains. Even if the protection rate is clearly lower in the older population, severe disease requiring hospitalisation and fatal outcome is reduced by $50 \%$ among the vaccinated population $[41,42]$.

\subsection{Severity and Course of the Disease}

No reports are available on influenza virus infections by blood products.

\subsection{Therapy and Prophylaxis}

Three antiviral products for the treatment of influenza virus infections are authorised in Germany. Due to adverse reactions, the M2 ion channel blocker amantadine is hardly used. Rimantadine, another member of this class of active ingredients, has fewer side-effects, but is not authorised in Germany. These adamantanes are only effective against influenza A viruses and very rapidly contribute to the development of resistant virus variants [43]. The markedly more effective neuraminidase inhibitors oseltamivir and zanamivir can help shorten the phase of the disease and reduce the symptoms if administered in time (within $24 \mathrm{~h}$ after the occurrence of the symptoms if possible) [44]. Nearly all H5N1 isolates from Vietnam and Thailand were adamantine-resistant, whereas most of the H5N1 isolates from Indonesia and China were adamantine-sensitive [45]. The majority of H5N1 viruses from South-East Asia from 2004 were sensitive to the neuraminidase inhibitors oseltamivir and zanamivir. A number of
$\mathrm{H} 5 \mathrm{~N} 1$ isolates were also sensitive to both classes of antiviral substances [19]. Both human and H5N1 viruses may show resistance to oseltamivir, but may be sensitive to zanamivir [ 46 , 47]. Therefore, continued resistance testing should be carried out both for human and for H5N1 strains.

\subsection{Transmissibility}

Influenza is typically transmitted by air or direct contact. Transmissions of human influenza viruses by blood and blood products have so far not been reported, not even during pronounced influenza epidemics. To protect the medical staff in the blood donor services, the decisions on the protection of medical staff adopted by the Ausschuss für biologische Arbeitsstoffe (ABAS, Committee for Biological Substances) should be applied in a way suitable for the situation during an influenza epidemic [48].

\subsection{Frequency of Administration, Type and Amount of Blood Products}

No reports are available so far which show any evidence for a transmission of human influenza viruses by blood products or plasma components.

\section{Blood Products}

\subsection{Infectious Load of the Starting Material and Test Methods}

The symptoms of an infection with human influenza virus give rise to the assumption that extrapulmonary tissue is infected, which is caused by viraemia. Such a viraemia could be identified several times by isolation of the viruses from the blood. Virus isolation could not only be performed during the symptomatic phase of serious courses of infection [49], but also as early as before the onset of the clinical symptoms during a normal course of the disease $[50,51]$. These detections of virus, however, remain limited to isolated cases.

So far, only few data is available on the occurrence of viraemia during an $\mathrm{H} 5 \mathrm{~N} 1$ infection. However, since severe diarrhoea could be observed in which virus detection was positive, it must be assumed that viraemia can occur with this virus type as well. Such a viraemia is observed in connection with high viral load and fatal outcome [52]. Whether the cases available are isolated cases or whether a general statement can be made remains to be clarified.

In conclusion, it can be stated that viraemia is possible in case of an influenza virus infection, even though the probability is low for the human virus type in case of a normal course of the disease. For H5N1 infections, the situation is judged differently: Based on the prolonged incubation period of up to 7 days 
and the apparently more frequent dissemination of the viruses in the blood, the risk potential is rated higher. What remains unclear, however, both for human and for avian influenza viruses, is whether the introduction of virus into the blood circulation will lead to an infection of the blood recipient. In case of a natural infection, the influenza viruses enter the body via the respiratory epithelium where they replicate. So far, available data on the effectiveness of transmission via the blood are not sufficient. This question should be taken into account in future studies.

\subsection{Methods for Removal and Inactivation of the Infectious Agent}

Influenza viruses belong to the group of enveloped viruses and are, therefore, inactivated by lipid solvents which are also used e.g. in S/D methods. Transmission of influenza viruses by plasma derivatives can therefore be ruled out, above all thanks to the use of physical and chemical depletion and inactivation steps during manufacture [53].

\subsection{Feasibility and Validation of Procedures for Removal/ Inactivation of the Infectious Agent}

In principle, human influenza isolates can be used for the validation of the manufacturing procedures for plasma components. Since different levels of antibody prevalence against influenza $\mathrm{A} / \mathrm{H} 1 \mathrm{~N} 1, \mathrm{~A} / \mathrm{H} 2 \mathrm{~N} 2$, and $\mathrm{A} / \mathrm{H} 3 \mathrm{~N} 2$ as well as influenza $\mathrm{B}$ viruses are present in the population, this should be taken into account in validating the different methods.

\section{Assessment}

According to the present state of knowledge, viraemia is observed only in serious courses of infection with human influenza viruses. This viraemia can usually be detected only as late as the first occurrence of symptoms of the disease such as fever. Infections with avian influenza A/H5N1 virus are characterised by the fact that they coincide with a high percentage of severe clinical symptoms and that, in case of fatal outcome, virus can be detected in all organs. It can be assumed that H5N1 infections in humans involve viraemia. Nothing is known about the onset of this viraemic phase following infection. Since the incubation period is 1-7 days for previously observed cases of disease, and is, as a rule, 2-5 days, it can be assumed that the viraemic phase is $7-10$ days.
In principle, it can be assumed that plasma components are safe both with regard to human influenza viruses and with regard to avian influenza virus. Special steps during the annual influenza epidemics with human influenza viruses with regard to safety of cellular, non-inactivated blood components are not indicated.

Because of their significance for the guarantee of the population's medical care in the pandemic case, blood donor services would have to be involved in the plans of the competent Federal and 'Länder' Authorities (authorities based on the federal state), and thus in the information flow. Since many of the blood donor services also operate beyond the boundaries of the 'Länder', it is necessary to co-ordinate the efforts between all 'Länder' authorities involved.

For the pandemic case, a framework should also be created enabling the blood donor services to co-ordinate their work as fast as possible. In agreement with the competent 'Länder' authorities, blood donor services will then be able to take steps to guarantee the blood component supply under pandemic conditions too, depending on the current epidemiological situation. Plans have been made to establish an agreement pursuant to section 3 subsection 2 of the Transfusionsgesetz (German Transfusion Act) laying down the details of mutual support in the event of disasters and other emergencies. Such an agreement is currently being compiled by the organisations that run the blood donor services.

This paper was completed on March 19, 2007 and approved by the German Advisory Committee Blood (Arbeitskreis Blut) on May 30, 2007. It was compiled by the members of the subgroup 'Assessment of Pathogens Transmissible by Blood' of the German Advisory Committee Blood:

Dr. Johannes Blümel

Prof. Dr. Reinhard Burger

Dr. Christian Drosten

Dr. Albrecht Gröner

Prof. Dr. Lutz Gürtler

Dr. Margarethe Heiden

PD Dr. Martin Hildebrandt

Prof. Dr. Dr. Bernd Jansen

Dr. Horst Klamm

Dr. Thomas Montag-Lessing

Dr. Ruth Offergeld

Prof. Dr. Georg Pauli

Prof. Dr. Rainer Seitz

Dr. Uwe Schlenkrich

Dr. Volkmar Schottstedt

Dr. Hannelore Willkommen

Prof. Dr. Carl-Heinz Wirsing von König

with the special support from Dr. Brunhilde Schweiger (Robert KochInstitut) 


\section{References}

1 Wright PF, Webster RG: Orthomyxoviruses; in Fields BN, Knipe DM, Howley PM, et al (eds): Fields Virology, 4th ed. Philadelphia, Lippincott Williams and Wilkins, 2001, pp $1533 \mathrm{ff}$.

2 Scholtissek C: Stability of infectious influenza A viruses at low $\mathrm{pH}$ and at elevated temperature. Vaccine 1985;3(suppl 1):215-218.

-3 Fouchier RA, Munster V, Wallensten A, Bestebroer TM, Herfst S, Smith D, Rimmelzwaan GF, Olsen B, Osterhaus AD: Characterization of a novel influenza A virus hemagglutinin subtype (H16) obtained from black-headed gulls. J Virol 2005;79:2814-2822.

4 Rota PA, Wallis TR, Harmon MW, Rota JS, Kendal AP, Nerome K: Cocirculation of two distinct evolutionary lineages of influenza type B virus since 1983. Virology 1990;175:59-68.

$\checkmark 5$ Nerome R, Hiromoto Y, Sugita S, Tanabe N, Ishida M, Matsumoto M, Lindstrom SE, Takahashi T, Nerome K: Evolutionary characteristics of influenza B virus since its first isolation in 1940: dynamic circulation of deletion and insertion mechanism. Arch Virol 1998;143:1569-1583.

6 Scholtissek C, Rohde W, Von Hoyningen V, Rott R: On the origin of the human influenza virus subtypes H2N2 and H3N2. Virology 1978;87:13-20.

7 Kawaoka Y, Krauss S, Webster RG: Avian-tohuman transmission of the PB1 gene of influenza A viruses in the 1957 and 1968 pandemics. J Virol 1989;63:4603-4608.

8 World Health Organization: Avian Influenza. www.who.int/csr/disease/avian_influenza/en/index .html.

9 Lyytikäinen O, Hoffmann E, Timm H, Schweiger B, Witte W, Vieth U, Ammon A, Petersen LR: Influenza A outbreak among adolescents in a ski hostel. Eur J Clin Microbiol Infect Dis 1998;17:128-130.

10 Thomas P, Riffelmann M, Schweiger B, Dominik S, von Konig $\mathrm{CH}$ : Fatal influenza A virus infection in a child vaccinated against influenza. Pediatr Infect Dis J 2003;22:201-202.

-11 Laing R, Slater W, Coles C, Chambers S, Frampton C, Jackson R, Jennings L, Karalus N, Mills G, Murdoch D, Town I: Community-acquired pneumonia in Christchurch and Waikato 1999-2000: microbiology and epidemiology. N Z Med J 2001;114:488-492.

12 Oliveira EC, Marik PE, Colice G: Influenza pneumonia: a descriptive study. Chest 2001;119:17171723 .

13 de Jong MD, Bach VC, Phan TQ, Vo MH, Tran TT, Nguyen BH, Beld M, Le TP, Truong HK, Nguyen VV, Tran TH, Do QH, Farrar J: Fatal avian influenza A (H5N1) in a child presenting with diarrhea followed by coma. N Engl J Med 2005;352:686-691.

14 Beigel JH, Farrar J, Han AM, Hayden FG, Hyer R, de Jong MD, Lochindarat S, Nguyen TK, Nguyen TH, Tran TH, Nicoll A, Touch S, Yuen KY; Writing Committee of the World Health Organization (WHO) Consultation on human influenza A/H5: Avian influenza A (H5N1) infection in humans. N Engl J Med 2005;353:1374-1385.

15 Yu H, Shu Y, Hu S, Zhang H, Gao Z, Chen H, Dong J, Xu C, Zhang Y, Xiang N, Wang M, Guo Y, Cox N, Lim W, Li D, Wang Y, Yang W: The first confirmed human case of avian influenza A (H5N1) in Mainland China. Lancet 2006;367(9504):84.

16 Webster RG: Influenza: An Emerging Disease. Emerg Infect Dis 1998;4:436-441.

17 Webster RG: The importance of animal influenza for human disease. Vaccine 2002;20(suppl 2):16-20.
Gregory V, Bennett M, Orkhan MH, Al Hajjar S, Varsano N, Mendelson E, Zambon M, Ellis J, Hay A, Lin YP: Emergence of influenza A (H1N2) reassortant viruses in the human population during 2001. Virology 2002;300:1-7.

19 Fauci AS: () Seasonal and pandemic influenza preparedness: science and countermeasures. J Infect Dis 2006;194(suppl 2):S73-S76.

20 Zucs P, Buchholz U, Haas W, Uphoff H: Influenza associated excess mortality in Germany, 1985-2001. Emerg Themes Epidemiol 2005;2:6.

21 Arbeitsgemeinschaft Influenza (AGI): Saisonberichte. www.influenza.rki.de/agi.

22 Thompson WW, Shay DK, Weintraub E, Brammer L, Cox N, Anderson LJ, Fukuda K: Mortality associated with influenza and respiratory syncytial virus in the United States. JAMA 2003;289:179-186.

23 Schweiger B, Zadow I, Heckler R: Antigenic drift and variability of influenza viruses. Med Microbiol Immunol 2002;191:133-138

24 Schweiger B: Molecular characterization of human influenza viruses - a look back on the last 10 years. Berl Munch Tierarztl Wochenschr 2006;119:167-178.

25 Schweiger B: Nationale und globale Influenzasurveillance als Basis der jährlichen Impfstoffempfehlung. Bundesgesundheitsbl Gesundheitsforsch Gesundheitsschutz 2001;44:1153-1161.

26 Coonrod JD, Karathanasis P, Betts RF, Donofrio JC: Enzyme-linked immunosorbent assay of core antigens for clinical diagnosis of influenza. J Med Virology 1988;25:399-409.

27 Johnston SLG, Siegel CS: A comparison of direct immunofluorescence, shell vial culture, and conventional cell culture for the rapid detection of influenza A and B. Diagn Microbiol Infect Dis 1991;14: 131-134.

28 Gleaves CA, Brown JA: Detection of influenza A in clinical specimens and cell culture fluid by a commercial EIA. Clin Diagn Virol 1993;1:123-127.

29 Ruest A, Michaud S, Deslandes S, Frost EH: Comparison of the Directigen Flu A+B test, the QuickVue Influenza test, and clinical case definition to viral culture and reverse transcription-PCR for rapid diagnosis of influenza virus infection. J Clin Microbiol 2003;41:3487-3493.

30 Booth S, Baleriola C, Rawlinson WD: Comparison of two rapid influenza $\mathrm{A} / \mathrm{B}$ test kits with reference methods showing high specificity and sensitivity for influenza A infection. J Med Virol 2006;78:619-622.

31 Donofrio JC, Coonrod JD, Davidson JN, Betts RF: Detection of influenza A and B in respiratory secretions with the polymerase chain reaction. PCR Meth Applicat 1992;1:263-268.

32 Wright KE, Wilson GAR, Novosad D, Dimock C, Tan D, Weber JM: Typing and subtyping of influenza viruses in clinical samples by PCR. J Clin Microbiol 1995;33(5):1180-1184.

33 Claas ECJ, Sprenger MJW, Kleter GEM, van Beek R, Quint WGV, Masurel N: Type-specific identification of influenza viruses A, B and C by the polymerase chain reaction. J Virol Methods 1992;39: 1-13.

34 Yamada A, Imanishi J: Detection of influenza B virus in throat swabs using the polymerase chain reaction. Acta Virol 1992;36:320-325.

-35 Schweiger B, Lange I, Heckler R, Willers H, Schreier E: Rapid detection of influenza A neuraminidase subtypes by cDNA amplification coupled to a simple DNA enzyme immunoassay. Arch Virol 1994;139:439-444.
6 Cherian T, Bobo L, Steinhoff MC, Karron RA, Yolken RH: Use of PCR-enzyme immunoassay for identification of influenza A virus matrix RNA in clinical samples negative for cultivable virus. J Clin Microbiol 1994;32:623-628.

37 Zhang WD, Evans DH: Detection and identification of human influenza viruses by the polymerase chain reaction. J Virol Methods 1991;33:165-189.

38 Schweiger B, Zadow I, Heckler R, Timm H, Pauli G: Application of a fluorogenic PCR assay for typing and subtyping of influenza viruses in respiratory samples. J Clin Microbiol 2000;38:1552-1558.

39 WHO Global Influenza Preparedness Plan. The Role of WHO and Recommendations for National Measures before and during Pandemics. $\mathrm{WHO} / \mathrm{CDS} / \mathrm{CSR} / \mathrm{GIP} / 2005.5$.

40 Bekanntmachung der Richtlinien zur Gewinnung von Blut und Blutbestandteilen und zur Anwendung von Blutprodukten (Hämotherapie) gemäß $\S \S 12$ und 18 des Transfusionsgesetzes (TFG) (Novelle 2005) vom 19. September 2005. Bundesanzeiger (Sonderheft) Nr. 209a, Jahrgang 57, vom 05.11.2005.

41 Nichol KL: Complications of influenza and benefits of vaccination. Vaccine 1999;17(suppl 1):S47-S52.

42 Vu T, Farish S, Jenkins M, Kelly H: A meta-analysis of effectiveness of influenza vaccine in persons aged 65 years and over living in the community. Vaccine 2002;20:1831-1836.

43 Hayden FG: Antiviral resistance in influenza viruses - implications for management and pandemic response. N Engl J Med 2006;354:785-788.

44 Hayden FG, Pavia AT: Antiviral management of seasonal and pandemic influenza. J Infect Dis 2006; 194(suppl 2):S119-126.

45 Cheung CL, Rayner JM, Smith GJ, Wang P, Naipospos TS, Zhang J, Yuen KY, Webster RG, Peiris JS, Guan Y, Chen H: Distribution of amantadine-resistant $\mathrm{H} 5 \mathrm{~N} 1$ avian influenza variants in Asia. J Infect Dis 2006;193:1626-1629.

46 Baz M, Abed Y, McDonald J, Boivin G: Characterization of multidrug-resistant influenza $\mathrm{A} / \mathrm{H} 3 \mathrm{~N} 2$ viruses shed during 1 year by an immunocompromised child. Clin Infect Dis 2006;43:1555-1561.

47 Le QM, Kiso M, Someya K, Sakai YT, Nguyen TH, Nguyen KH, Pham ND, Ngyen HH, Yamada S, Muramoto Y, Horimoto T, Takada A, Goto H, Suzuki T, Suzuki Y, Kawaoka Y: Avian flu: isolation of drug-resistant H5N1 virus. Nature 2005;437:1108.

48 Ausschuss für biologische Arbeitsstoffe (ABAS): Arbeitsschutz beim Auftreten von nicht impfpräventabler Influenza unter besonderer Berücksichtigung des Atemschutzes. Beschluss 609. www.baua.del nn_15408/de/Themen-von-A-Z/Biologische-Arbeitsstoffe/TRBA/pdf/Beschluss-609.pdf.

49 Lehmann NI, Gust ID: Viraemia in influenza. A report of two cases. Med J Aust 1971;2:1166-1169.

50 Stanley ED, Jackson GG: Viremia in Asian influenza. Trans Assoc Am Phys 1966;79:376-387.

51 Khakpour M, Saidi A, Naficy K: Proved viraemia in Asian influenza (Hong Kong variant) during incubation period. Br Med J 1969;4:208-209.

52 de Jong MD, Simmons CP, Thanh TT, Hien VM, Smith GJ, Chau TN, Hoang DM, Chau NV, Khanh TH, Dong VC, Qui PT, Cam BV, Ha do Q, Guan Y, Peiris JS, Chinh NT, Hien TT, Farrar J: Fatal outcome of human influenza A (H5N1) is associated with high viral load and hypercytokinemia. Nat Med 2006;12:1203-1207.

53 Kreil TR, Unger U, Orth SM, Petutschnig G, Kistner O, Poelsler G, Berting A: H5N1 influenza virus and the safety of plasma products. Transfusion 2007:47:452-459. 